\title{
Ensaio
}

\section{Romance de entretenimento no Prêmio Jabuti 2020: inclusão ou exclusão?}

Entertainment novel at the Jabuti 2020 Award: inclusion or exclusion?

\section{Tagiane Mai'}

' Universidade NOVA de Lisboa, Lisboa, Portugal

Em março de 2020, uma polêmica se instaurou no meio editorial brasileiro, quando a Câmara Brasileira do Livro (CBL) anunciou algumas mudanças nas categorias do Prêmio Jabuti, o mais tradicional e prestigiado prêmio literário do país. Dentre elas, destacou-se a divisão da categoria Romance em dois novos segmentos: Romance Literário e Romance de Entretenimento. De imediato, vieram à tona elogios e críticas à iniciativa por parte de editores, escritores, curadores, leitores e a grande mídia. Neste ensaio, objetivamos apresentar os desdobramentos dessa mudança, discutindo os seus aspectos mais significativos, a aferição das virtudes estéticas de ambas as categorias, os posicionamentos favoráveis e contrários à decisão e o estado atual da ficção brasileira e do seu mercado editorial.

O Prêmio Jabuti é promovido desde 1958 e representa o reconhecimento do leitor e da comunidade intelectual brasileira aos autores, editoras e profissionais envolvidos na produção de um livro. Por sua abrangência, é considerado o mais completo prêmio do livro no Brasil, abrangendo vinte categorias, divididas em quatro eixos: 
(1) Eixo Literatura: Conto, Crônica, História em Quadrinhos, Infantil, Juvenil, Poesia, Romance Literário e Romance de Entretenimento;

(2) Eixo Ensaios: Artes; Biografia, Documentário e Reportagem; Ciências; Ciências Humanas; Ciências Sociais; e Economia Criativa;

(3) Eixo Livro: Capa, Ilustração, Projeto Gráfico e Tradução;

(4) Eixo Inovação: Fomento à Leitura e Livro brasileiro publicado no exterior. Há também a premiação do "Livro do Ano", concedida à obra que tiver recebido a maior nota entre as categorias dos eixos Literatura e Ensaios.

Como sabemos, os prêmios literários proporcionam uma série de vantagens: carregam consigo uma marca de legitimação literária a escritores iniciantes; aumentam a visibilidade de um escritor e da sua editora, despertando mais atenção da mídia; desencadeiam um aumento nas vendas das obras indicadas e premiadas, representando um incremento financeiro seja para o autor, seja para a casa publicadora; abrem espaço a novos contratos de edição ou mesmo a possibilidade de tradução para outras línguas, ampliando as oportunidades de trabalho aos profissionais do livro; enfim, estimulam, de uma forma ou de outra, o desenvolvimento da literatura nacional.

De acordo com Regina Zilberman (2017), em artigo sobre o romance brasileiro contemporâneo conforme os prêmios literários, a consagração representada por um prêmio sinaliza também as tendências do meio editorial, podendo constituir-se em um ótimo termômetro para medir o estado atual de uma literatura. A autora observa que, no Brasil, o gênero romance é um dos mais prestigiados entre os prêmios literários, o que aponta para a importância e primazia desse gênero entre autores e público leitor.

É sob essa perspectiva que se realiza a subdivisão da categoria Romance em duas novas opções a partir da $62^{a}$ edição do Prêmio Jabuti. A inclusão do romance de entretenimento responde a um anseio de renovação do prêmio e atualização com o que acontece e se produz na indústria editorial brasileira, tal como afirma Pedro 
Almeida ${ }^{1}$, presidente do Conselho Curador do Jabuti à época do lançamento do edital de inscrição: "Buscamos com essa inclusão reconhecer os autores nacionais de ficção para que eles se tornem tão populares quanto Tolkien (fantasia), Shelley e Bram Stoker (terror), Julio Verne (aventura), Charlotte Brontë e José Mauro Vasconcelos (romances sentimentais) e Agatha Christie (Mistério)"2 . De fato, o que se observou foi que, apesar de o romance de entretenimento sempre ter sido inscrito no Jabuti - e em outras premiações de literatura -, nunca foi premiado nessas seis décadas.

A respeito da separação entre romance literário e de entretenimento, Almeida explica que eles se diferenciam no aspecto "invenção" literária: enquanto o primeiro foca na arte de uso da língua, o segundo traz uma narrativa que prende o leitor pelo seu enredo. "Para um romance literário, temos um júri especializado em crítica literária, mas este não poderia julgar os romances de entretenimento com a mesma régua." ${ }^{3}$ Daí a proposição de uma categoria específica para contemplar os textos que se identificam com esse segundo grupo.

O regulamento ${ }^{4}$ da $62^{\text {a }}$ edição do Prêmio Jabuti assim definiu o Romance Literário: "Narrativa ficcional em prosa, geralmente longa, cujo enredo se desenvolva relacionando personagens numa sequência temporal. Pode narrar sobre todo tema e sob qualquer enfoque. O júri desta categoria irá avaliar as

\footnotetext{
${ }^{1} \mathrm{O}$ editor Pedro Almeida renunciou ao cargo de curador do prêmio em maio deste ano, após repercussão negativa de um post em sua rede social, em que questionava o número de mortes devido à covid-19 naquele momento. Na oportunidade, escritores, editores e intelectuais vieram a público manifestar sua indignação com o post, e o coletivo Virgínia, formado por mais de 200 mulheres profissionais do mercado editorial, publicou uma carta aberta pedindo a renúncia do curador.

${ }^{2}$ Disponível em: https://www.premiojabuti.com.br/noticias/estao-abertas-as-inscricoes-para-o-premiojabuti-2020/. Acesso em: 18 dez. 2020.

${ }^{3}$ Disponível em: https://www.publishnews.com.br/materias/2020/03/25/o-que-e-romance-deentretenimento-a-nova-categoria-do-premio-jabuti. Acesso em: 18 dez. 2020. Vale ainda observar que o então presidente do Conselho Curador possui a sua própria editora (Faro Editorial), a qual publica, entre outros, os gêneros policial e terror, o que nos leva a pensar se não estaríamos diante de um conflito de interesses.
}

${ }^{4}$ Disponível em: https://www.premiojabuti.com.br/regulamento-premio-jabuti-2020_atualizado.pdf. Acesso em: 18 dez. 2020. 
qualidades do texto, privilegiando a forma, a arte literária." (grifo nosso). Os critérios a serem considerados pelo júri para a avaliação dessa categoria são apresentados na Figura 1, a seguir.

Figura 1 - Critérios apreciados na categoria Romance Literário

\begin{tabular}{|c|c|}
\hline 1. & $\begin{array}{c}\text { ORIGINALIDADE DE TEMA RELACIONADO À FORMA E/OU } \\
\text { ESTILO }\end{array}$ \\
\hline 2. & TÉCNICA NARRATIVA E ESTRUTURA \\
\hline 3. & $\begin{array}{c}\text { DESENVOLVIMENTO DA AÇÃO E CONSTRUÇÃO DOS } \\
\text { PERSONAGENS }\end{array}$ \\
\hline
\end{tabular}

Fonte: https://www.premiojabuti.com.br/regulamento-premio-jabuti-2020 atualizado.pdf. Acesso em: 20 dez. 2020.

Já a definição apresentada para o Romance de Entretenimento foi a seguinte:

Narrativa ficcional em prosa, geralmente longa, cujo enredo se desenvolva relacionando personagens numa sequência temporal. Aqui devem ser inscritos, principalmente, os romances de gênero, de entretenimento, quando se considerar que a obra é voltada para um público mais amplo. Por exemplo: policial, ficção científica, terror, romance sentimental/de amor, humor, suspense, aventura, fantasia, entre outros. $O$ júri desta categoria irá avaliar as qualidades do enredo, privilegiando o conteúdo, a trama. (grifo nosso).

Os critérios de análise adotados pelo júri (Figura 2), por sua vez, assemelham-se aos do Romance Literário. A diferença agora é que o segundo critério passa a ser o principal aspecto a ser considerado, enquanto a capacidade de engajamento do leitor figura logo em seguida, junto da originalidade da trama. O terceiro critério é o mesmo em ambos os segmentos. Ou seja, embora haja um cruzamento de critérios, a relevância dos aspectos a serem apreciados pelo júri é coerente com o entendimento adotado para cada categoria. 
Figura 2 - Critérios apreciados na categoria Romance de Entretenimento

\begin{tabular}{|c|c|}
\hline 1. & $\begin{array}{c}\text { TÉCNICA NARRATIVA E ESTRUTURA RELACIONADAS AO } \\
\text { GÊNERO }\end{array}$ \\
\hline 2. & ORIGINALIDADE E CAPACIDADE DE ENGAJAR O LEITOR \\
\hline 3. & DESENVOLVIMENTO DA AÇÃO E CONSTRUÇÃO DOS \\
& PERSONAGENS \\
\hline
\end{tabular}

Fonte: https://www.premiojabuti.com.br/regulamento-premio-jabuti-2020 atualizado.pdf. Acesso em: 20 dez. 2020.

A respeito da nomenclatura adotada, Pedro Almeida explica que o termo "romance de gênero", uma das possibilidades aventadas pelo Conselho Curador, poderia provocar estranhamento entre o público brasileiro, já que ainda é pouco conhecido no país. Apesar de a expressão derivar do inglês e ser usual na literatura norte-americana, na língua portuguesa não contamos com a distinção entre "gender" para se referir ao masculino ou feminino e "genre" para falar de tipo. Assim, a expressão poderia gerar ambiguidade entre tipo ou identidade e não ser devidamente compreendida.

Outra opção, o termo "romance comercial" poderia soar pejorativo, devido à carga de preconceito que carrega. De fato, o termo "literatura comercial" muitas vezes é empregado no Brasil para se referir a livros de qualidade literária duvidosa. Os livros de Paulo Coelho, por exemplo, embora contem com uma receptividade internacional muito grande, são muitas vezes taxados de literatura comercial, por serem considerados como de baixo valor estético e de apelo comercial.

"Romance de entretenimento", então, pareceu ser o termo mais adequado ao Conselho Curador, alegando-se a existência de estudos acadêmicos que explicam o termo, tal como o artigo de Almeida (2015), que trata do gênero entretenimento nas décadas de 1930 e 1940 no Brasil. O ex-curador indica ainda a 
leitura de "Commercial and literary fiction: what's the difference?" 5 , texto que elenca as principais diferenças entre ficção literária e comercial.

Por seu turno, os críticos à iniciativa argumentaram que a inclusão do romance de entretenimento seria, na realidade, uma demonstração do elitismo subjacente ao prêmio, pois partiria de um entendimento equivocado sobre alta e baixa literatura. Tal divisão evidenciaria, afinal, a distinção existente entre forma e conteúdo, erudito e popular, artístico e comercial, colocando o romance literário num pedestal e relegando ao romance de entretenimento um lugar menor. É o que podemos depreender das palavras da jornalista Taize Odelli, autora de um blog sobre resenhas de livros:

Diferenciar 'romance literário' de 'romance de entretenimento' é uma forma de continuar com essa separação esdrúxula entre o que é mais comercial e o que é considerado 'arte'. É, implicitamente, dizer que um romance mais popular não tem a forma e estética que se considera 'literária', quando na verdade tem sim, e muito. Mas além da estética, tem também diversão. $E$, ao mesmo tempo, não dá para dizer que o que é 'literário' não pode divertir, não pode entreter, quando o papel principal da literatura é entreter enquanto te faz refletir. ${ }^{6}$

Boa parte da crítica se dirigiu, afinal, aos responsáveis por chancelar o que seria ou não literatura - "literatura com letra maiúscula" -, questionando o posicionamento subjetivo e misturado a gostos pessoais por parte do júri. É nesse sentido que argumenta a pesquisadora Emanuela Siqueira:

Toda a estrutura de poder da premiação é que deve ser questionada, quem serão os/as jurados/as que decidirão quais romances são puro entretenimento e os que são sisudos e literários. Quais diferenças há entre eles? Minha maior curiosidade é saber de que lugares e premissas estéticas partem essas pessoas que julgarão os títulos inscritos. É preciso, sim, personificar essas estruturas de poder para justamente entender de onde esses indivíduos falam e quais são seus interesses. ${ }^{7}$

\footnotetext{
${ }^{5}$ Disponível em: https://www.spreadtheword.org.uk/commercial-literary-fiction-whats-the-difference/. Acesso em: 20 dez. 2020.

${ }^{6}$ Disponível em: https://www.posfacio.com.br/2020/03/19/literatura-o-premio-jabuti-e-o-romance-deentretenimento/. Acesso em: 20 dez. 2020.

7 Disponível em: https://www.posfacio.com.br/2020/03/19/literatura-o-premio-jabuti-e-o-romance-deentretenimento/. Acesso em: 20 dez. 2020.
} 
O escritor Raphael Montes, que tem se destacado como roteirista e autor de literatura policial, evitou se manifestar sobre a controvérsia logo que esta veio à tona, mas, após a divulgação dos resultados do prêmio - ele foi o vencedor da categoria Romance de Entretenimento, com o livro Uma mulher no escuro (Companhia das Letras, 2019) -, declarou a respeito da polêmica:

se de um lado temos o 'romance de entretenimento', é de se supor que na outra categoria disputem os 'romances de aborrecimento', aqueles dedicados a arrancar bocejos do leitor, deixá-lo impaciente ou de saco cheio. Em sentido oposto, se consideramos a categoria 'romance literário', temos a clara impressão de que os romances que entretêm não são (nem podem ser) literatura. Sem dúvida, um impasse desagradável ${ }^{8}$.

Embora esse posicionamento soe um tanto reducionista, restringindo a questão a uma visão dualista, vale refletirmos sobre a problemática que o escritor levanta. De fato, a categorização de um livro pode ser um tanto complicada, pois reduzi-lo a uma única classificação pode apagar outros pertencimentos possíveis, além de eliminar a possibilidade de cruzamento, intersecção ou justaposição entre categorias.

Contudo, como ressalta o professor Bernardo Bueno (2020), coordenador do curso de Escrita Criativa da PUCRS, gêneros e categorias dizem respeito a influências e tradições. Nesse sentido, permitem identificar semelhanças entre famílias de textos e reconhecer a tradição literária da qual são oriundos. Para Bueno, o mais importante, neste caso, é lembrar que a literatura é plural e que as categorias não são uma prisão.

De sua parte, os editores reconhecem a existência da divisão literário versus entretenimento no mercado editorial. Os escritores, por sua vez, já perceberam que o terror, a fantasia, a ficção científica, a distopia, o insólito, os medos e os monstros, ao se apresentarem em situações extraordinárias, tratam justamente de assuntos humanos - e, por que não, atuais.

\footnotetext{
${ }^{8}$ Disponível em: https://veja.abril.com.br/blog/raphael-montes/literatura-ou-entretenimento/. Acesso em: 20 dez. 2020.
} 
Dessa forma, se por ora não é possível acabar com tal separação, não seria o caso de valer-se dela para tirar algum proveito, isto é, tomá-la para si e promover a difusão do gênero entretenimento, dos seus autores e de toda a sua produção artística, por meio de um prêmio da dimensão do Jabuti?

A fim de encontrar respostas para o presente impasse, recorremos ao clássico Formação da literatura brasileira: momentos decisivos, de Antonio Candido, publicado originalmente em 1957, para nos valermos das noções de sistema literário e de tradição. Em linhas gerais, a literatura se constitui como sistema literário, segundo Candido, quando possui um conjunto organizado de produtores literários, um conjunto de receptores e um mecanismo transmissor, que liga uns e outros.

Nesse sentido,

Quando a atividade dos escritores de um dado período se integra em tal sistema, ocorre outro elemento decisivo: a formação da continuidade literária, espécie de transmissão da tocha entre corredores, que assegura no tempo o movimento conjunto, definindo os lineamentos de um todo. É uma tradição, no sentido completo do termo, isto é, transmissão de algo entre os homens, é o conjunto de elementos transmitidos, formando padrões que se impõem ao pensamento ou ao comportamento, e aos quais somos obrigados a nos referir, para aceitar ou rejeitar. Sem esta tradição, não há Literatura, como fenômeno de civilização. (Candido, 1999, p. 24).

Isto é, a tradição estabelece as obras e autores que formam o cânone brasileiro e que influenciam o que se entende/aceita como padrão nesse sistema. Contudo, também funciona como argumento a ser seguido ou rejeitado por aqueles que promoverão a continuidade literária, num movimento semelhante ao da própria história da literatura e das gerações literárias. Esse parece ser o caso com o qual nos defrontamos. Ao lado de um paradigma estabelecido, temos um conjunto de escritores cujos temas e questões propostas relacionam-se com os interesses da cultura nacional do momento - e que não necessariamente vão seguir esse paradigma.

Como bem observou Zilberman no estudo citado, entre os anos 1930 e 1960 no Brasil, por exemplo, predominou a literatura social e de cunho regionalista; já entre 1970 e 1980, a tendência era a exposição dos dramas políticos decorrentes da ditadura 
militar e da repressão político-ideológica; os textos produzidos em décadas mais recentes, por sua vez, mostraram-se menos engajados e mais globalizados, como a autoficção e o memorialismo (fictício ou não). Poderíamos aventar, então, se no momento atual o romance de entretenimento é que estaria se inscrevendo no sistema literário do país.

Em relação ao conjunto de receptores, podemos pensar na noção de comunidades de leitores, proposta por Roger Chartier em A ordem dos livros (1998). Para o historiador do livro e da leitura, uma comunidade de leitores seria um grupo de pessoas que reúnem maneiras, comportamentos, técnicas e hábitos de leitura similares, sendo que cada comunidade prioriza e/ou legitima um texto. Havendo várias comunidades, é de se supor, portanto, que tenhamos uma pluralidade de textos validados, conforme as práticas sociais de cada comunidade.

Dessa forma, não é possível julgar uma literatura como melhor ou pior que outra; elas apenas circulam em esferas literárias diferentes, contando com maior ou menor receptividade de acordo com o público que as recebe. A tensão existente entre o que é e o que não é literário não colabora com a proposta de valorização de livros, autores e editoras no amplo universo do mercado editorial brasileiro. O que é válido, em nossa opinião, é não desprezar o que já está consagrado, mas também não desconsiderar as novas correntes, afinal elas chegam ao mercado com muito fôlego e trazem consigo uma comunidade de leitores cada vez mais numerosa e engajada com seus autores. Assim, mais uma vez, lembramos um dos tópicos levantados em aula, a respeito da importância de, como profissionais do livro, sermos flexíveis e estarmos abertos às disposições do meio em que atuamos, lembrando ainda que nenhum público leitor deve ser menosprezado.

Por fim, entendemos que o Prêmio Jabuti se mostra sensível à atual onda renovadora da literatura brasileira contemporânea, conferindo notoriedade a um gênero que ainda é visto com ressalvas e que permanece à margem de muitos prêmios literários. Os prêmios literários, aliás, mostram-se merecedores de estudo na medida 
em que são sinais do prestígio que uma obra, autor, gênero ou categoria adquire dentro do meio editorial.

Ainda, poder-se-ia investigar se, após a inclusão da categoria, houve um acréscimo no número de publicações inscritas nesse gênero, se o Romance de Entretenimento vai se manter nas edições futuras do prêmio - sobretudo após as críticas e a saída de seu curador - ou então qual o perfil dos autores de entretenimento, quais as principais temáticas abordadas e como se caracteriza a sua comunidade de leitores.

\section{REFERÊNCIAS}

ALMEIDA, Leandro Antonio de. Repercussão da expansão da ficção popular no brasil dos anos 1930. Revista de História (São Paulo), n. 173, p. 359-393, 2015. Disponível em: https://www.scielo.br/scielo.php?pid=S0034-83092015000200359\&script=sci abstract \&tlng=pt. Acesso em: 19 dez. 2020.

BUENO, Romance de entretenimento? Nova categoria do Prêmio Jabuti reflete atual diversidade da ficção. GaúchaZH, 19 nov. 2020. Disponível em: https://gauchazh.clicrbs.com.br/cultura-e-lazer/livros/noticia/2020/11/romance-deentretenimento-nova-categoria-do-premio-jabuti-reflete-atual-diversidade-da-ficcaockhowdwtt002h0137iiil9xtj.html. Acesso em: 19 dez. 2020.

CANDIDO, Antonio. Formação da Literatura Brasileira: Momentos decisivos. 6. ed. Belo Horizonte: Itatiaia, 2000. Disponível em: https://edisciplinas.usp.br/pluginfile.php/ 4261753/mod resource/content/1/AC\%20-\%20FLB\%20Pref\%C3\%A1cios\%20e\%20 Introdu\%C3\%A7\%C3\%A30.pdf. Acesso em: 19 dez. 2020.

CANDIDO, Antonio. Iniciação à Literatura Brasileira. 3. ed. São Paulo: Humanitas Publicações - Fflch/USP, 1999.

CHARTIER, Roger. A ordem dos livros: Leitores, autores e bibliotecas na Europa entre os séculos XIV e XVIII. 2. ed. Tradução: Mary Del Priore. Brasília: Editora da Universidade de Brasília, 1998.

ZILBERMAN, Regina. O romance brasileiro contemporâneo conforme os prêmios literários (2010-2014). Estudos de Literatura Brasileira Contemporânea, n. 50, p. 424443, 2017. Disponível em: https://periodicos.unb.br/index.php/estudos/article/view. Acesso em: 19 dez. 2020.

\section{Tagiane Mai}

Especialista em Revisão de Textos

tagiane.revisao@gmail.com 